\title{
Gp100 Protein (184V)
}

National Cancer Institute

\section{Source}

National Cancer Institute. gp100 Protein (184V). NCI Thesaurus. Code C29555.

A recombinant peptide derived from the human melanoma antigen glycoprotein 100 (gp100) with potential use in cancer immunotherapy. gp100 protein(184V) has a valine substitution at position 184 . Vaccination with this peptide may evoke a cytotoxic $T$ lymphocyte $(C T L)$ response against tumor cells expression the gp100 antigen. 